Research Article

Journal of Extension Education

Vol. 32 No. 4, 2020

DOI:https://doi.org/10.26725/JEE.2020.4.32.6613-6620

\title{
Association of Socio-demographic Characteristics with Knowledge, Attitude and Practice towards Solid Waste Management
}

\author{
R. Geetha* and S. Rajalakshmi*
}

\begin{abstract}
The aim of this study was to explore the knowledge, attitudes and practices (KAP) of women's solid waste management Practices in Rameshwaram, Ramanthapuram District, Tamilnadu, India, to provide a framework for experts and decision-makers to establish or enhance realistic solid waste management (SWM) strategies. A cross-sectional analysis was conducted among 400 women respondents, data were collected using a standardized questionnaire on socio-economic characteristics and SWM. Results suggested that there was correlation between age, population, occupation and annual income of women with KAP to minimize, reuse, recycle and recover SWM. Implementing training programmes and encouraging municipalities and decision-makers to boost women's environmental performance could significantly promote SWM strategies.
\end{abstract}

Keywords: Solid waste management; Socio-economic characteristics; Knowledge; Attitude; Practices; Tamil Nadu.

\section{INTRODUCTION}

India, with a growing population and living standards, is struggling to cope with the simultaneous acceleration of waste generation. Appropriate management of household solid waste involves a variety of approaches such as recycling, urban landfilling and resource reduction (Minghua et al., 2009; Bhattacharjee, 2018). Provision of public training provides a cost-effective and compelling solution to improving the contribution of residents to household waste reduction and recycling schemes (De Feo and De Gisi, 2010). The commitment of people to solid waste recycling has been increased through regular training sessions. It should be noted that SWM plans, especially complicated programmes, might not be well understood by some residents without offering adequate educational programmes. Such incomprehension may adversely affect public involvement in waste separation and recycling activities.

Demographic features of people in a given group can indeed affect their understanding of waste disposal (Purcell and Magette, 2010). In order to achieve an effective

\footnotetext{
*Department of Home Science Extension and Education, Avinashilingam Institute for Home Science and Higher Education for Women, Coimbatore, Tamil Nadu, India.
}

Received : 06-05-2021; Accepted : 20-07-2021 
solid waste management system, knowing public concerns, awareness and behaviour, is important. The assessment and enchantment of women at the level of KAP will greatly promote their contribution to the reduction and separation of household waste, thereby promoting SWM recycling programmes (Laor et al., 2018).

The present study was therefore intended to draw attention to the role of women in SWM in Rameshwaram, Ramanthapuram district, Tamil Nadu, India. Specifically, we calculated the awareness, attitude and level of practice of Rameshwaram women in relation to SWM strategies. The demographic characteristics of respondents, such as age, community, occupation and annual income, which allow Rameshwaram women to be characterized by groups based on similar behavioral attitudes, were evaluated in this study. In addition, the effect of educational intervention programme on solid waste management on the success of women in SWM has been assessed.

\section{METHODOLOGY}

The study was carried out purposively in Rameshwaram, Ramanthapuram district, Tamil Nadu, India. The issues of plastic littering are quite common in Rameswaram Island throughout the year. Though the usage of plastic is banned, it has not been effectively enforced. Moreover, Rameswaram is one of the important tourist / holy destinations in south India. This Coastal tourism destination has been combined by a unique resource combination with land and three seas (Bay of Bengal, Arabian Sea and Indian Ocean) (Mallick et al., 2020). Hence, present study was an attempt to establish the suitable strategies for the development of SWM in the study area.

\section{Data collection}

This study used a semi-structured questionnaire to gather data on knowledge, attitude and practices regarding household solid waste management among women. The socioeconomic status was assessed and the responses were measured with numbers and analyzed with statistical procedures. Information regarding socio-demographic characteristics of the participants, their perception about different methods of waste disposal and its harmful effects on health and environment etc. were documented. Likewise, participant's opinion regarding segregation of waste at the source and responsibility of keeping the community clean were recorded to assess their attitudes. The household's method of waste collection and storage practices were observed with the help of a checklist. In all the respective domains the responses were scored.

\section{Assessment before the intervention programme}

A questionnaire was prepared to find out the Knowledge level of solid waste management in the selected area. The questionnaire was divided into subgroups as follows: Socio economic profile, Waste generation and disposal of household waste, Challenges faced by the households due to accumulation of house hold waste, prevailing environmental condition in selected area, Garbage collection service and KAP on solid waste management. 
Association of Socio-demographic Characteristics with Knowledge, Attitude and Practice towards Solid Waste Management

\section{Educational intervention programme on solid waste management}

An education intervention programme on solid waste management was conducted to select women according to the plan of work at a convenient time for the attendants. The programme included lectures by experts with videos, demonstration in composting yard field visits, pamphlets and booklet distribution.

\section{Assessment after the intervention programme}

Post assessment of educational intervention programme was done to know the effectiveness of the intervention programme organised on solid waste management. Feedback forms were provided to the women households. Feedback was gathered in the aspects of clarity in subjects delivered by the resource person, punctuality of conduct of programme and overall coordination of the programme.

\section{Assessment of KAP on Solid Waste Management}

1. Knowledge gained on Solid Waste Management

After the educational intervention, knowledge gained was assessed using a knowledge check based on various aspects on waste recycling process, bio degradable waste, diseases due to pollution, impacts of human health, impact of using plastic bags,3R's process, composting, vermicomposting.

\section{Attitude towards SWM}

Attitude towards waste management was developed based on Likert rating scale.
Responses were obtained on a five point scale:- strongly agree, Agree, neutral, Disagree and strongly disagree with scores of 5,4,3,2,1.

\section{Practices followed by the selected respondents}

Practice was measured based upon the segregation of waste. Segregation of waste is important criterion as the amount of waste generated causes immense problem to the environment. Household waste should be separated daily into different dustbins for the different categories of waste such as wet and dry waste which should be disposed of separately. Wet wastes, which consist of leftover foodstuff, vegetables, peels etc., should be put in an organic waste converter called Green Bin, and it is converted to composting. Dry waste consisting of cans, aluminium foils, plastics, metal, glass and paper should be recycled.

\section{Sampling Method}

There are 21 wards in Rameswaram. Among them, 8 wards were selected for the study namely, Kariyur, Sambhai, Maruthupandinagar, Cherankottai, Annanagar, Ramartheertham, Murugaivadi, and Sallimalai. The study was done based on certain criteria such as solid waste generation, disposal behaviour of waste and enormity of other activities near waste collection points in the area. For the study, 400 household women, of which 50 women representing each ward were chosen as respondents. A survey was conducted on the socio economic profile of these household women, their problems related to disposal of solid waste and the 
awareness level on solid waste management were obtained. The survey results were then analysed.

\section{Data Analysis}

Data were analysed using SPSS version 20.0. Further to identify the relationship between of socio-economic characteristics and KAP scores ANOVA test was used.

\section{FINDINGS AND DISCUSSION}

Relationship between Socio-economic characteristics and KAP towards SWM

In the present study, an analysis of knowledge scores was performed with respect to socio-economic characteristics. For the assessment of knowledge score-before the intervention programme, a questionnaire was prepared and administered to find out the Knowledge level of solid waste management in the selected area. For the assessment of knowledge score-after the intervention programme, feedback forms were provided to the women households to find out the effectiveness of the intervention programme organised on solid waste management.

After the educational intervention, knowledge gained was assessed.

The ANOVA test with regards to knowledge score-before and after intervention for age categories and community

Table 1. Analysis of Knowledge scores with respect to Socio-economic characteristics

\begin{tabular}{|c|c|c|c|c|c|c|c|c|}
\hline \multirow{2}{*}{\multicolumn{2}{|c|}{ Socio-economic characteristics }} & \multirow{3}{*}{$\begin{array}{l}\text { No. } \\
30 \\
\end{array}$} & \multirow{2}{*}{\multicolumn{2}{|c|}{$\begin{array}{l}\text { Knowledge } \\
\text { Score-Before }\end{array}$}} & $\mathbf{F}$ & \multicolumn{2}{|c|}{$\begin{array}{l}\text { Knowledge } \\
\text { Score-After }\end{array}$} & $F$ \\
\hline & & & & & & & & \\
\hline \multirow{3}{*}{ Age } & $20-30$ & & \begin{tabular}{|c|} 
Mean \\
2.27 \\
\end{tabular} & $\begin{array}{l}\text { S.D } \\
3.78 \\
\end{array}$ & \multirow{3}{*}{$11.902^{* *}$} & 27.57 & 5.87 & \multirow{3}{*}{$24.762^{* *}$} \\
\hline & $31-40$ & 54 & .00 & .00 & & 31.00 & .00 & \\
\hline & $41-50$ & 16 & .31 & .48 & & 21.81 & 8.62 & \\
\hline \multirow{3}{*}{ Community } & $\mathrm{SC}$ & 5 & 10.20 & 2.39 & \multirow{3}{*}{$481.922^{* *}$} & 15.20 & 2.86 & \multirow{3}{*}{$35.634^{* *}$} \\
\hline & $\mathrm{MBC}$ & 30 & .17 & .38 & & 26.10 & 7.76 & \\
\hline & $\mathrm{BC}$ & 65 & .26 & .57 & & 30.63 & .99 & \\
\hline \multirow{4}{*}{ Occupation } & Business & 8 & .50 & .53 & \multirow{4}{*}{$.941 \mathrm{NS}$} & 14.38 & 4.93 & \multirow{4}{*}{$39.006^{* *}$} \\
\hline & Private job & 12 & .08 & .29 & & 29.83 & 2.48 & \\
\hline & Government job & 10 & .00 & .00 & & 31.00 & .00 & \\
\hline & Fishing & 70 & .97 & 2.70 & & 29.53 & 4.17 & \\
\hline \multirow{3}{*}{ Income } & $20000-30000$ & 5 & .20 & .45 & \multirow{3}{*}{$1.304 \mathrm{NS}$} & 11.20 & 1.92 & \multirow{3}{*}{$47.443^{* *}$} \\
\hline & $30001-40000$ & 25 & .16 & .37 & & 29.08 & 4.07 & \\
\hline & $40001-50000$ & 70 & .97 & 2.70 & & 29.53 & 4.17 & \\
\hline
\end{tabular}

**Significant $p<0.01$

NS Non-significant $p>0.05$ 
Association of Socio-demographic Characteristics with Knowledge, Attitude and Practice towards Solid Waste Management

status showed $P<0.01$, indicating a significant difference (Table 1 ). The $f$-value with regard to knowledge score-before for occupation and income range showed $\mathrm{P}>0.05$, indicating a non-significant difference in the knowledge score-before intervention for occupation and income range, while, the f-value with regard to knowledge score-after intervention for occupation and income range showed $P<0.01$, indicating a significant difference in the knowledge score-after intervention for occupation and income range. Thus, from the results it is clear that intervention programmes showed significant improvement in the knowledge score with respect to socioeconomic characteristics towards SWM.
Table 2. Comparison of knowledge scores before and after the intervention

\begin{tabular}{|c|c|c|c|c|}
\hline & Mean & S.D & No. & $\mathbf{t}$ \\
\hline $\begin{array}{c}\text { Knowledge } \\
\text { score-before }\end{array}$ & .73 & 2.29 & 100 & $50.184^{* *}$ \\
\hline & Mean & S.D & No. & $\mathbf{t}$ \\
\hline $\begin{array}{c}\text { Knowledge } \\
\text { score-after }\end{array}$ & 29.23 & 4.73 & 100 & - \\
\hline
\end{tabular}

* Paired samples t-test

** - Significant at $1 \%$ level.

The comparison of knowledge scores before and after the intervention showed that average knowledge score before intervention was 2.29 which had increased to 4.73 after intervention (Table 2). Further, the $t$ value

Table 3. Analysis for Attitude scores with respect to Socio-economic characteristics

\begin{tabular}{|c|c|c|c|c|c|c|c|c|}
\hline \multicolumn{2}{|c|}{ Socio-economic characteristics } & \multirow[t]{2}{*}{ No. } & \multicolumn{2}{|c|}{$\begin{array}{c}\text { Attitude } \\
\text { Score-Before }\end{array}$} & \multirow[t]{2}{*}{$\mathbf{F}$} & \multicolumn{2}{|c|}{$\begin{array}{c}\text { Attitude } \\
\text { Score-After }\end{array}$} & \multirow[t]{2}{*}{$F$} \\
\hline & & & Mean & S.D & & Mean & S.D & \\
\hline \multirow{3}{*}{ Age } & $20-30$ & 30 & 40.47 & 1.41 & \multirow{3}{*}{$90.357^{* *}$} & 27.03 & 1.73 & \multirow{3}{*}{$117.648^{* *}$} \\
\hline & $31-40$ & 54 & 35.94 & 1.75 & & 32.11 & 1.83 & \\
\hline & $41-50$ & 16 & 35.50 & 1.21 & & 36.25 & 3.02 & \\
\hline \multirow{3}{*}{ Community } & SC & 5 & 40.20 & .45 & \multirow{3}{*}{$40.277^{* *}$} & 24.80 & .45 & \multirow{3}{*}{$88.894^{* *}$} \\
\hline & MBC & 30 & 34.60 & 1.35 & & 35.50 & 2.35 & \\
\hline & $\mathrm{BC}$ & 65 & 38.22 & 2.25 & & 29.78 & 2.25 & \\
\hline \multirow{4}{*}{ Occupation } & Business & 8 & 35.63 & 1.51 & \multirow{4}{*}{$27.472^{* *}$} & 37.75 & 3.06 & \multirow{4}{*}{$48.676^{* *}$} \\
\hline & Private job & 12 & 34.92 & 1.00 & & 34.75 & 1.82 & \\
\hline & Government job & 10 & 33.40 & .52 & & 34.60 & .52 & \\
\hline & Fishing & 70 & 38.36 & 2.23 & & 29.43 & 2.53 & \\
\hline \multirow{3}{*}{ Income } & 20000- 30000 & 5 & 34.80 & 1.30 & \multirow{3}{*}{$36.241^{* *}$} & 39.40 & 2.70 & \multirow{3}{*}{$82.394^{* *}$} \\
\hline & $30001-40000$ & 25 & 34.56 & 1.39 & & 34.72 & 1.28 & \\
\hline & $40001-50000$ & 70 & 38.36 & 2.23 & & 29.43 & 2.53 & \\
\hline
\end{tabular}

${ }^{* *}$ Significant $p<0.01$ 
for knowledge score with respect to socioeconomic characteristics towards SWM was found to be 50.184 which is significant at $1 \%$ level. Hence it is inferred that intervention programme had strongly influenced the relationship between knowledge and socioeconomic characteristics towards SWM.

An ANOVA test with regard to Attitude score-before and after intervention for the socio-economic characteristics (age, community, occupation and income) showed $P<0.01$, indicating a significant difference in the Attitude score-after intervention with respect to socio-economic characteristics (Table 3). Thus, from the results it is clear that intervention programme showed significant improvement in the Attitude score with respect to socio-economic characteristics towards SWM.

Table 4. Comparison of attitude scores. before and after intervention

\begin{tabular}{|c|c|c|c|c|}
\hline & Mean & S.D & No. & $\mathbf{t}$ \\
\hline $\begin{array}{c}\text { Attitude } \\
\text { score-before }\end{array}$ & 37.23 & 2.65 & 100 & $83.860^{* *}$ \\
\hline & Mean & S.D & No. & $\mathbf{t}$ \\
\hline $\begin{array}{c}\text { Attitude } \\
\text { score-after }\end{array}$ & 68.48 & 1.85 & 100 & - \\
\hline
\end{tabular}

* Paired samples t-test

** - Significant at $1 \%$ level.

The comparison of attitude scores. before and after the intervention showed that average attitude score before intervention which was 37.23 had increased to 68.48 after

Table 5. Analysis of Practice scores with respect to Socio-economic Characteristics

\begin{tabular}{|c|c|c|c|c|c|c|c|c|}
\hline \multicolumn{2}{|c|}{ Socio-economic characteristics } & \multirow[t]{2}{*}{ No. } & \multicolumn{2}{|c|}{$\begin{array}{c}\text { Practice } \\
\text { Score-Before }\end{array}$} & \multirow[t]{2}{*}{$\mathbf{F}$} & \multicolumn{2}{|c|}{$\begin{array}{c}\text { Practice } \\
\text { Score-After }\end{array}$} & \multirow[t]{2}{*}{$\mathbf{F}$} \\
\hline & & & Mean & S.D & & Mean & S.D & \\
\hline \multirow{3}{*}{ Age } & $20-30$ & 30 & 21.90 & 1.30 & \multirow{3}{*}{$178.772^{* *}$} & 29.10 & 1.30 & \multirow{3}{*}{$175.042^{* *}$} \\
\hline & $31-40$ & 54 & 23.89 & 2.43 & & 27.11 & 2.43 & \\
\hline & $41-50$ & 16 & 33.38 & 1.59 & & 13.94 & 5.01 & \\
\hline \multirow{3}{*}{ Community } & SC & 5 & 20.20 & 1.30 & \multirow{3}{*}{$155.916^{* *}$} & 30.80 & 1.30 & \multirow{3}{*}{$86.845^{* *}$} \\
\hline & MBC & 30 & 30.53 & 3.61 & & 18.50 & 6.31 & \\
\hline & $\mathrm{BC}$ & 65 & 22.52 & .97 & & 28.48 & .97 & \\
\hline \multirow{4}{*}{ Occupation } & Business & 8 & 34.63 & .52 & \multirow{4}{*}{$400.956^{* *}$} & 9.88 & 2.85 & \multirow{4}{*}{$403.017^{* *}$} \\
\hline & Private job & 12 & 31.42 & 1.44 & & 19.00 & 2.70 & \\
\hline & Government job & 10 & 26.20 & 1.55 & & 24.80 & 1.55 & \\
\hline & Fishing & 70 & 22.36 & 1.16 & & 28.64 & 1.16 & \\
\hline \multirow{3}{*}{ Income } & $20000-30000$ & 5 & 34.60 & .55 & \multirow{3}{*}{$196.859^{* *}$} & 8.60 & 2.88 & \multirow{3}{*}{$202.737^{* *}$} \\
\hline & $30001-40000$ & 25 & 29.72 & 3.40 & & 20.48 & 4.71 & \\
\hline & $40001-50000$ & 70 & 22.36 & 1.16 & & 28.64 & 1.16 & \\
\hline
\end{tabular}

**Significant $p<0.01$ 
Association of Socio-demographic Characteristics with Knowledge, Attitude and Practice towards Solid Waste Management

intervention (Table 4). Moreover, the t value for attitude scores with respect to socio-economic characteristics towards SWM was found to be 83.860 which is significant at $1 \%$ level. Hence it is inferred that intervention programme had strongly influenced the relationship between attitude and socioeconomic characteristics towards SWM.

An ANOVA test with regard to practice score-before and after intervention for the socio-economic characteristics (age, community, occupation and income) showed $\mathrm{P}<0.01$, indicating a significant difference in the practice score-after intervention with respect to socio-economic characteristics (Table 5). Thus, from the results it is clear that intervention programme showed significant improvement in the practice score with respect to socio-economic characteristics towards SWM.

Table 6. Comparison of Practice Scores before and after intervention

\begin{tabular}{|c|c|c|c|c|}
\hline & Mean & S.D & No. & $\mathbf{t}$ \\
\hline $\begin{array}{c}\text { Practice } \\
\text { score-before }\end{array}$ & 24.81 & 4.35 & 100 & $43.645^{* *}$ \\
\hline $\begin{array}{c}\text { Practice } \\
\text { score-after }\end{array}$ & 50.41 & 1.95 & 100 & - \\
\hline
\end{tabular}

** - Significant at $1 \%$ level.

The comparison of practice scores before and after the intervention showed that average practice score before intervention was 24.81 which had increased to 50.41 after intervention (Table 6). Furthermore, the $t$ value for practice score with respect to socio-economic characteristics towards
SWM was found to be 43.645 which is significant at $1 \%$ level. Hence it is inferred that intervention programme strongly influenced the relationship between practice and socioeconomic characteristics towards SWM.

\section{CONCLUSION}

The outcome of the present study indicates that the composition of the waste produced reflected variations in the socioeconomic factors of the population. Socioeconomic factors such as age, community, occupation and income had a greater effect on the choice of disposal methods. It is therefore been proposed that efficient management of solid waste can be accomplished by raising environmental consciousness and promoting environmental education efforts.

\section{REFERENCES}

Bhattacharjee, S. (2018). 'Where goes the waste?' a Knowledge, Attitude, and Practice (KAP) study on disposal of household waste. International Journal of Science and Engineering, 3, 26-9.

De Feo, G, \& De Gisi, S. (2010). Public opinion and awareness towards MSW and separate collection programmes: a sociological procedure for selecting areas and citizens with a low level of knowledge. Waste Management, 30(6), 958-976.

Laor, P, Suma, Y, Keawdounglek, V, Hongtong, A., Apidechkul, T. \& Pasukphun, N. (2018). Knowledge, attitude and practice of municipal solid waste management among highland residents in Northern Thailand. Journal of Health Research,32, 123-131. 
Mallick, S, Rudra, S \& Samanta, R. (2020). Sustainable ecotourism development using SWOT and QSPM approach: A study on Rameswaram, Tamil Nadu. International Journal of Geoheritage and Parks, 8.

Minghua, Z, Xiumin, F, Rovetta, A, Qichang, H, Vicentini, F, \& Bingkai, L. (2009). Municipal solid waste management in Pudong New Area, China. Journal of Waste Management, 29, 1227-33.

Purcell, M, \& Magette, W. (2010). Attitudes and behaviour towards waste management in the Dublin, Ireland region. Waste Management, 30(10), 1997-2006. 